\title{
TOPOGRAPHY RESTORATION OF HISTORIC CITY RESEARCH
}

\author{
Lee Sung ho ${ }^{\mathrm{a}}$ Han Dong soo ${ }^{\mathrm{b}}$ \\ a Doctor’s course completion, Hanyang University Seoul - pana2000@naver.com \\ b Prof., Hanyang University Seoul - dsharn@hanyang.ac.kr
}

Commission I I, WG I I/3

KEY WORDS: Restoration, GIS, Buyeo, Sabi Capital City, Baekje

\begin{abstract}
:
The preservation of historic cities requires a balance between conservation and development because the urban structures of the old and new city are interwoven on same space. Existing restoration plans rely on old records and excavation reports and are based on the present topography. However, historic cities have undergone significant natural and anthropogenic topographic changes such as alluvial sediment accumulation and uneven terrain construction. Therefore, considering only the present topography is misleading. Thus, to understand a historic city's structure more appropriately, it is necessary to comprehend the ancient geographic environment. This study provides an analysis and GIS visualization of the ancient topography of a historic city, Sabi capital city of the Baekje Dynasty, which collapsed 1,500 years ago.
\end{abstract}

\section{INTRODUCTION}

The historic city of Buyeo is located in the central Korean Peninsula and was the Sabi capital city (538 - 660 AD), the last of the Baekje Dynasty (百濟, 18 BC - 663 AD). This was a golden age for the city in every fields: refined architecture; craft; art; religion; international exchange with China, Japan, India, and other southeast Asia ancient countries; and powerful royal dominion. However, despite the historicity of the Baekje Dynasty's splendid civilization, Buyeo's urbanization since the 1970s was undiscerning. In the middle 1990s, as the importance of Buyeo historic city was highlighted, the conservation versus development dilemma became an issue. The historic city management legislation includes the conservation of ruins, which were discovered underneath the present city, thus restricting further construction. Excavation has intermittently progressed for about 15 years, dotting the city. Yet, the historic city is only partially reconstructed through these efforts. The authorities vaguely predict that almost all major ruins are located just under the downtown of present Buyeo, where there are many modern structures. However, the lack of accurate estimates results in inefficient conservation and development, and significantly delays the historic city's preservation. For the past 10 years, on the basis of the limited archaeological data available, scholars postulated that the ancient urban structure produced a city with well-appointed gridiron roads. However, the evidence from the modern excavations continuously contradicts this theory. This study proposes the reconstruction of the ancient topography as a necessary tool in historic city restoration. The historic city of Buyeo is treated as an example, focusing on restoring the actual topography 1,500 years ago. Furthermore, the urban structure of the ancient capital city, Sabi, is investigated by analyzing this restored topography.

\section{NECESSITY AND METHOD OF TOPOGRAPHIC RESTORATION FOR HISTORIC CITIES}

Topographic restoration is necessary for three reasons. First, it provides interdisciplinary data, which complement current ineffective efforts. East Asian historic cities differ from those in Europe, such as Rome, that have been researched since the 15th century. Existing methods would require significant time and effort to produce actual results for the historic cities of East Asia. Therefore, alternative sources are required to complement the excavation data. Second, topographic restoration allows reinterpreting the excavation findings. Because topography has significantly changed during the development and modernization of the city, studies based solely on the present topography lead to misinterpretation of the value and stature of the excavated ruins. Hence, to appropriately reconstruct the historic city, it is necessary to understand the ancient topography. Third, topographic restoration provides information on land use during ancient times, which enables creating more efficient excavation plans. For example, the ancient streams' higher flooding limit and the buildable area are separated.

The topographic restoration procedure is divided into four stages adapted to the situation, period, and particular features of the historic city under study.

- Preparatory stage: artificial topography changes check and restoration range set.

- Data collection and computerization stage: humanistic data (e.g., old records, legends, old maps, locality names, local development history, survey, excavation, distribution chart of the excavation site), scientific data (e.g., geological features, hydrography, seawater activity, climatic changes, natural disasters, vegetation changes, ancient agricultural techniques, ancient vessels), data computerization (assimilating and preparing data for the geographic information system).

- Data analysis stage: comparative analysis of disparate data, deduction of natural topographic change order, and rules and hypothesis of topography restoration. 
- Restoration stage: establishing the appropriate restoration method (according to the particular characteristics of each historic city and considering the local geographic factors such as plains, mountains, and streams); Table 1 provides these features for the case study of Buyeo, adjusted to the restoration of the ancient topography 1,500 years ago.

\begin{tabular}{|c|c|c|}
\hline Factor & Procedure & Detail method \\
\hline \multirow{3}{*}{$\begin{array}{l}\text { Plains } \\
\& \\
\text { Mount } \\
\text { ains }\end{array}$} & $\begin{array}{l}\text { Earth surface } \\
\text { changes }\end{array}$ & $\begin{array}{l}\text { - Differences in altitude between the } \\
\text { present and old topography (extracted } \\
\text { data from excavation reports). } \\
\text { - Order of natural topographic changes } \\
\text { (comparative analysis based on } \\
\text { geological features and the known } \\
\text { altitude values for the ancient } \\
\text { topography). }\end{array}$ \\
\hline & $\begin{array}{l}\text { Primary } \\
\text { topographic } \\
\text { model (standard } \\
\text { time) }\end{array}$ & $\begin{array}{l}\text { - Creating a 3D topographic model } \\
\text { using the base map (e.g., AutoCAD, } \\
\text { ArcGIS Spatial analysis tool). }\end{array}$ \\
\hline & $\begin{array}{l}\text { Secondary } \\
\text { topographic } \\
\text { model } \\
\text { (restoration } \\
\text { time) }\end{array}$ & $\begin{array}{l}\text { - Modifying each XY-isometric point on } \\
\text { the primary model (the present altitude } \\
\text { to the ancient). } \\
\text { - Recreating the 3D topographic model } \\
\text { using the modified data (with GIS } \\
\text { interpolation or an alternative method). }\end{array}$ \\
\hline \multirow[t]{3}{*}{$\begin{array}{l}\text { Rivers } \\
\& \\
\text { Strea } \\
\text { ms }\end{array}$} & $\begin{array}{l}\text { Ancient river } \\
\text { boundaries }\end{array}$ & $\begin{array}{l}\text { - Reviewing overall river gradient of } \\
\text { target area. } \\
\text { - Gathering clues related with ancient } \\
\text { water level (river bank, docking facility, } \\
\text { old records, local legend etc.) } \\
\text { - Grasping water surface level value of } \\
\text { the clue (restoration time) and applying } \\
\text { each point through calculating the river } \\
\text { gradient value. } \\
\text { - Appling each ancient water surface } \\
\text { data to 3D topography model both } \\
\text { normal and flood season. }\end{array}$ \\
\hline & $\begin{array}{l}\text { Application of } \\
\text { ancient water } \\
\text { system data to } \\
\text { the model }\end{array}$ & $\begin{array}{l}\text { - Assuming a normal water level and } \\
\text { flood season for the ancient river. } \\
\text { - Estimating the ancient water level by } \\
\text { applying its altitude to the 3D model } \\
\text { (considering entire geomorphic grades). }\end{array}$ \\
\hline & $\begin{array}{l}\text { Ancient stream } \\
\text { way trace }\end{array}$ & $\begin{array}{l}\text { - Restoring steams using the } 3 \mathrm{D} \\
\text { restoration model (ArcGIS hydrology } \\
\text { tool). }\end{array}$ \\
\hline
\end{tabular}

Table 1 . The ancient topographic restoration process by geographic factors

\section{BUYEO ANCIENT TOPOGRAPHIC RESTORATION}

\subsection{Restoration range and base map setting}

Buyeo has significantly transformed since the 1970s to the great plain area observed today. In the 1970s, the entire area was flat, and during the 1980s, several environmental changes occurred: a dam on the upper river, an estuary dam on the lower river, riverbanks, large bridges, sand collection, and so on. Thus, to understand Buyeo's ancient topography, it is necessary to understand the sequence of these natural changes using a map predating the 1970s that does not contain artificial geomorphic changes. Here, a contour map of the year 1918 (scale: 1/25,000) is selected, because it includes a large amount of data and almost no error. This map is compared with the present one to identify the natural topographic changes until today, and then used as the base map to restore the ancient topography. In this study, the entire putative old city and the riverside area are restored, which parts were most radically altered.

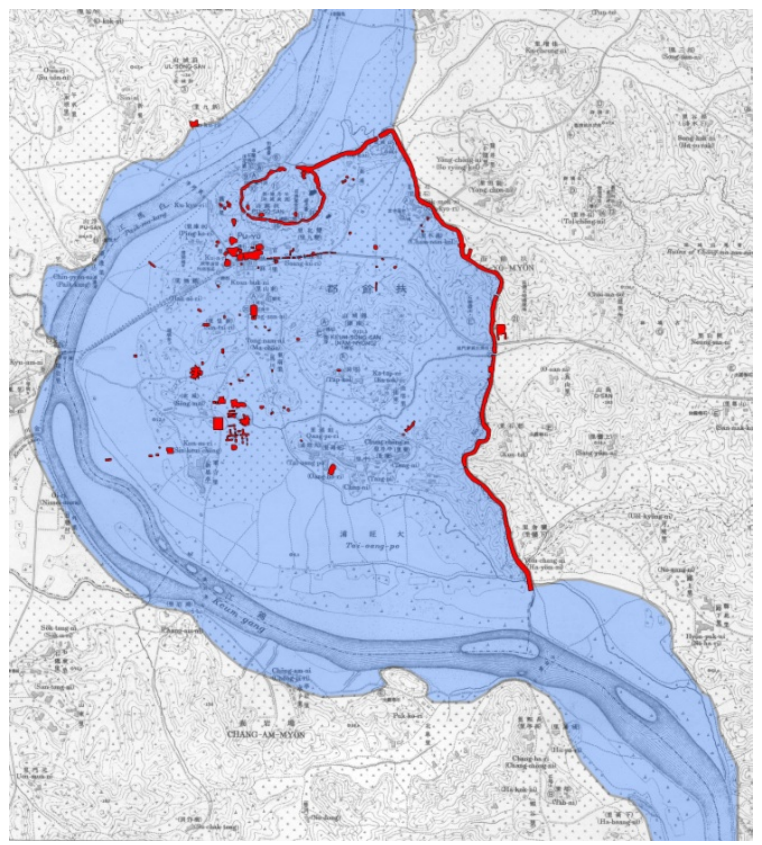

Figure 1. Base map and the restoration boundary

\subsection{Ancient topography analysis}

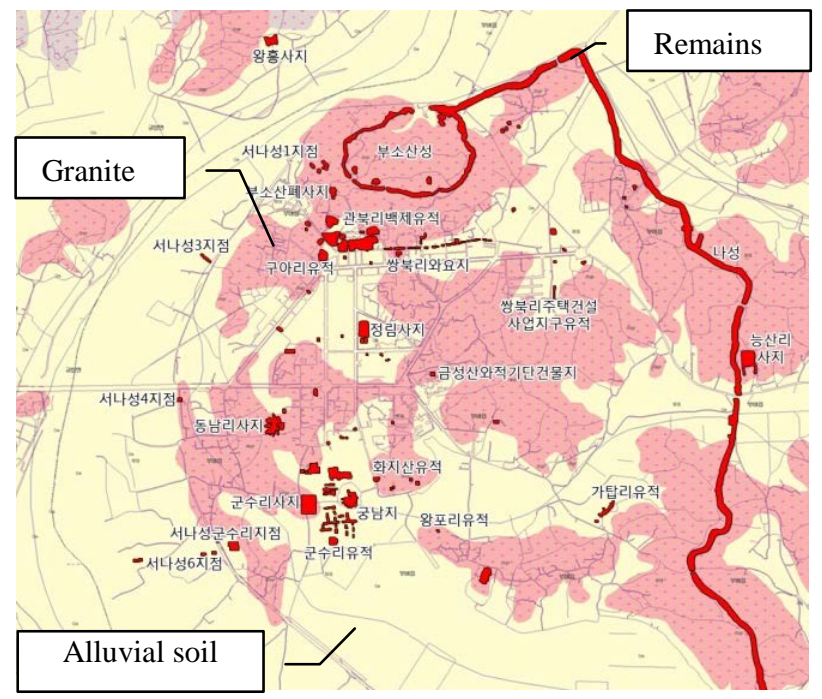

Figure 2. Geographical feature and remains

Until now, the large plain area of the historic city of Buyeo was regarded as a single geographical feature, covering many major ancient remains. However, it actually includes two different geological units, granite and alluvial soil. The ancient topographic data acquired from relevant excavation reports are grouped according to these units. Ancient remains are buried at depths between 0 to $1 \mathrm{~m}$ in the granite, whereas they are found between 2 to $4 \mathrm{~m}$ in alluvial land. Consequently, it is hypothesized that there no significant topographic change occurred in the granite areas during the last 1,500 years. 
Therefore, restoration should focus only the on alluvial covered areas.

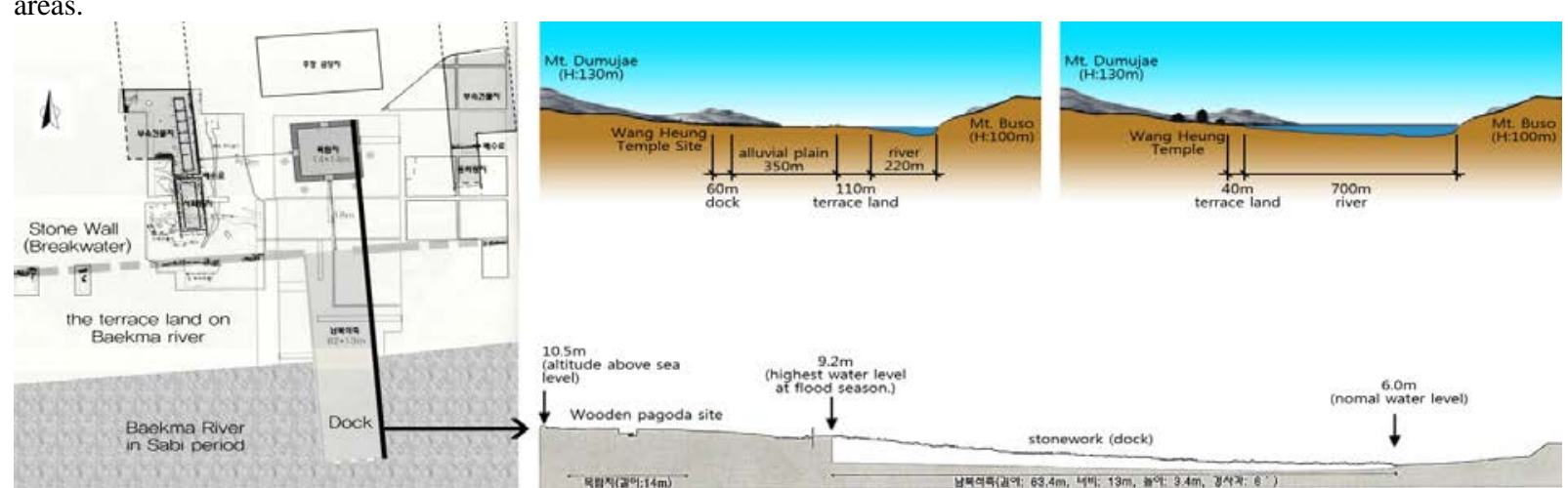

Figure 3. Wang-Heung temple ruins and the relative position of the ancient water level

Meanwhile, the ancient climate during these times was warmer and more humid than it is today, and the sea level was 6-7 m higher. This information is acquired from an analysis report on ancient breakwater ruins near the target area $60 \mathrm{~km}$ from the Yellow Sea as well as from the analysis of plant remains. The target area was located within a river-flow distance and was affected by sea tidal action before the estuary dam construction in the 1980s. As a result, during high tides, the river flowed slowly or even stopped, but at low tides, the river flowed very fast. Because the target area is located on the marginal point of tidal river, the upper river of the city shows in order. On the contrary, in the lower region, several sedimentation sequences are observed, which produced a thick sedimentary unit. The width of the present river reaches $300 \mathrm{~m}$. During the dry season, ships cannot cross the river because the riverbed is exposed. However, as per older records and legends, the river was the principal route for the ancient city. Hence, it seems that the river water level has declined during the last 1,500 years. According to this assumption, the investigation of the ruins on the ancient riverside area led to the discovery of the Wang-Heung temple site, located $350 \mathrm{~m}$ from the river and at the foot of a mountain. It contains some stonework ruins that probably functioned as an artificial bank and docking facility. On the basis of an old record, a Baekje king entered the temple by a ship. Hence, knowledge of the water level variability was available at the

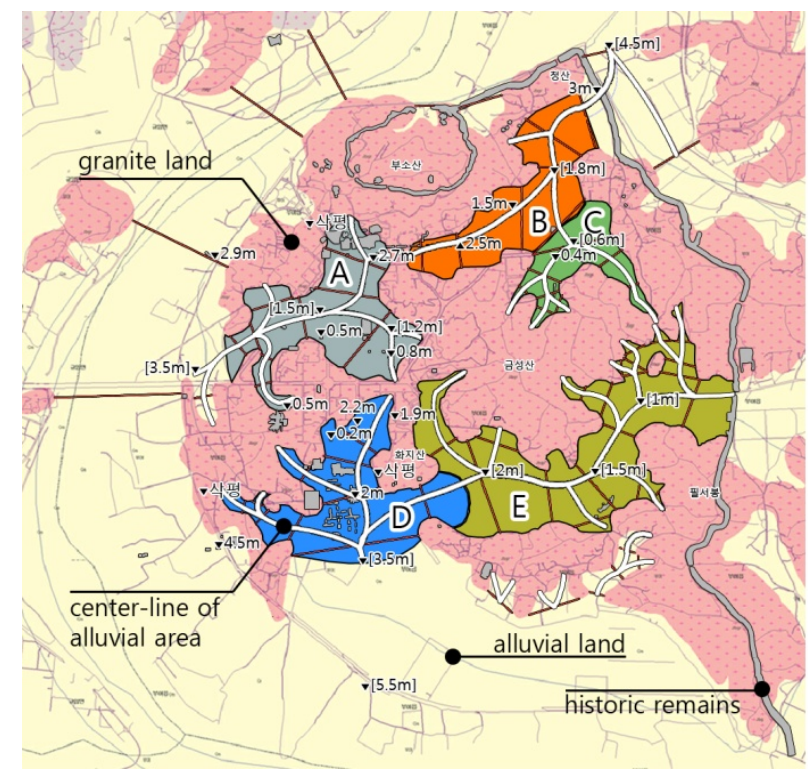

time of the temple's construction, since capital cities of the Baekje Dynasty were located near many large rivers, and the temple was constructed about 60 years after the establishment of the last capital city. Indeed, the ancient dock facility of the Wang-Heung temple site contains two water levels, adapted for the low- and high-level seasons. In addition, according to a Korean government analytic report, the overall river gradient value for the target area to be restored ranges from $1 / 5,000$ to $1 / 8,000$. There are two flood areas within the ancient city limits, which were created during floods owing to the poor drainage system. Lakes, where mud or clay layers were accumulated during ancient times, existed in these areas before the ancient city was constructed, suggesting that ancient river inundation during the flooding seasons transformed the lowstand areas into wetlands. Therefore, the plain areas were unsuitable for construction but could be used as rice fields as they were rich in nutrients. Furthermore, the bank ruins excavated near one of the ancient lakes suggest that the natural lake was used as an artificial pond.

\subsection{The ancient plain of Buyeo}

To reconstruct the ancient topography, the alluvial covered areas are divided into five groups (A-E), considering the river and seawater influence. The ancient topography is restored

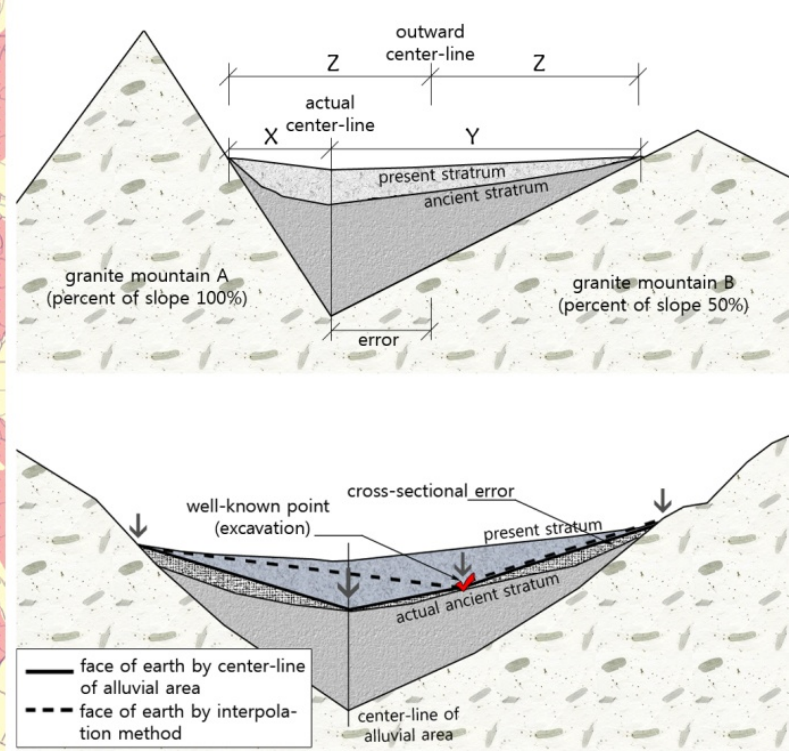

Figure 4. Ancient topographic analysis around the alluvial areas 
using the burial depth values acquired from the excavation report. However, the control points of the ancient surface are too few to allow accurate estimates through GIS interpolation. Therefore, this study proposes a new method that converts point to linear values. From a cross-section of the alluvial areas, the sedimentary thickness of the meeting point between the alluvial and river terrace of the backward mountain is almost zero, and the center point of the alluvial exhibits the greatest thickness. By this simple principle, the center point of the alluvial is calculated through a proportional equation using excavation data, two meeting points with the backward mountain, and the mean gradient in both sides of the mountains acquired from GIS spatial analysis. Subsequently, each cross-section diagram that contains a center point burial and a location value is combined with a branch-type line on the plain. Thus, the sediment thickness is maximum at the center of the alluvial area. Figure 5 presents a 3D topography model of the ancient topography using GIS and the center lines of five alluvial areas.

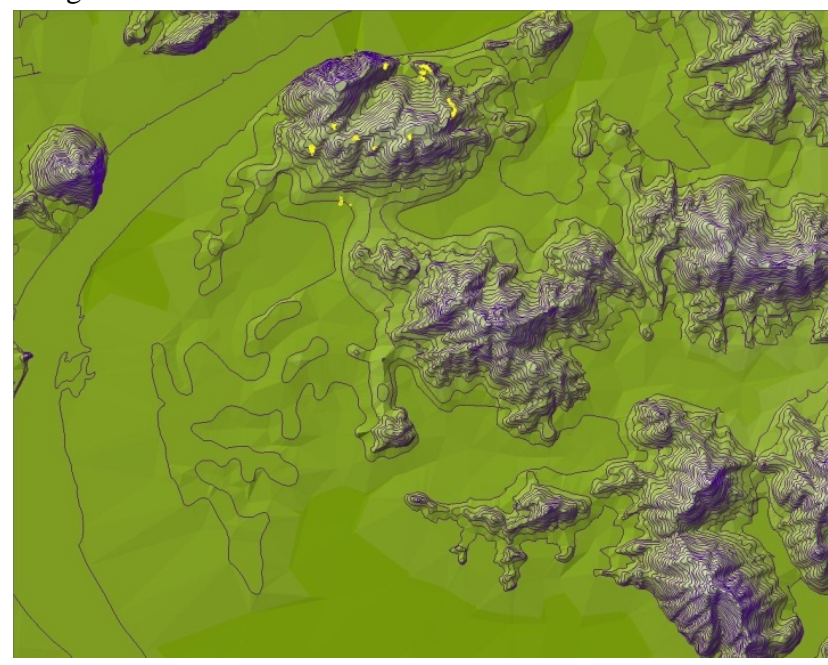

Figure 5. A restoration model of the ancient plain

\subsection{The ancient river of Buyeo}

The ancient river boundary is simply produced by filling the 3D model with water. The standard ancient water levels correspond

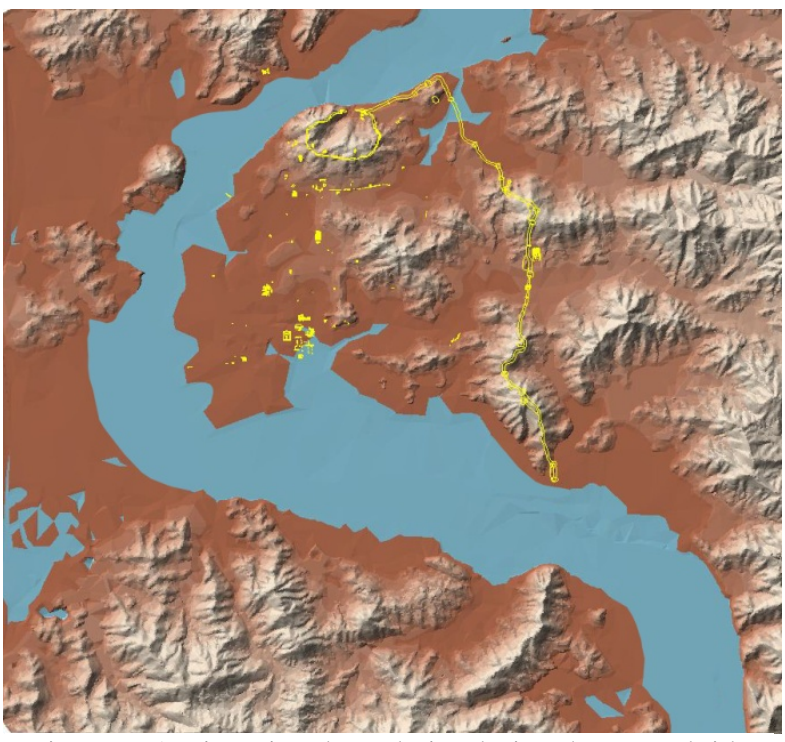

Figure 6. Ancient river boundaries during the normal tide season (water level is 6-4.5 m) to the starting and ending points of the stonework at the WangHeung temple site, and the average river gradient of $1 / 6,500$ is applied. During the normal and flooding seasons, in the north part of the target map, the water level corresponds to 6 and $9 \mathrm{~m}$, respectively. In the southeast part, the water level becomes 4.5 and $7.5 \mathrm{~m}$, respectively. Appling these data to the GIS, the ancient normal and flooding season topographic model produced is shown in Figures 6 and 7. The ancient river received greater water input and was formed more toward the inner part of the land than it is today. During the flooding season, river water penetrates into even some parts of the present downtown of Buyeo, and almost all of the lower alluvial area was inundated. The lower land was very wet because of the annual flooding. This correlates with old Chinese records. In addition, the descended folk story, which has been disregarded before as impossible on the basis of the present topography, is concordant with the restoration models. The old city buried inside the historic city Buyeo has been regarded as a wellordered grid-type city, as viewed from the present topography, irrespective of the geological features. However, the assumed uneven surface morphology and humid condition question this hypothesis, proving it necessary to consider the restoration model.

\subsection{Ancient steams and urban structure}

Streams on the restored model can be analyzed with the GIS hydrology analysis tool. The ancient natural waterways make it clearer to interpret historic remains in order to understand the ancient land use and the administrative district divisions of the old city. In the ancient capital city of Buyeo, there were four collecting basins. Therefore, the existing excavated ruins should be reconsidered and reinterpreted in view of the restored topography and identified streams. Figure 8 presents an example of this new interpretation method. This area receives a considerable amount of water from the mountains in the east. The plain area includes an ancient rampart across the steam basin, with the moat evident outside the wall ruins. Indeed, there are abundant water resources in this area, especially wider wall ruins than in the other plain ramparts. The evidence that the wall contacted directly with water suggests that the wall functioned as a bank facility. The rice field was supplied with

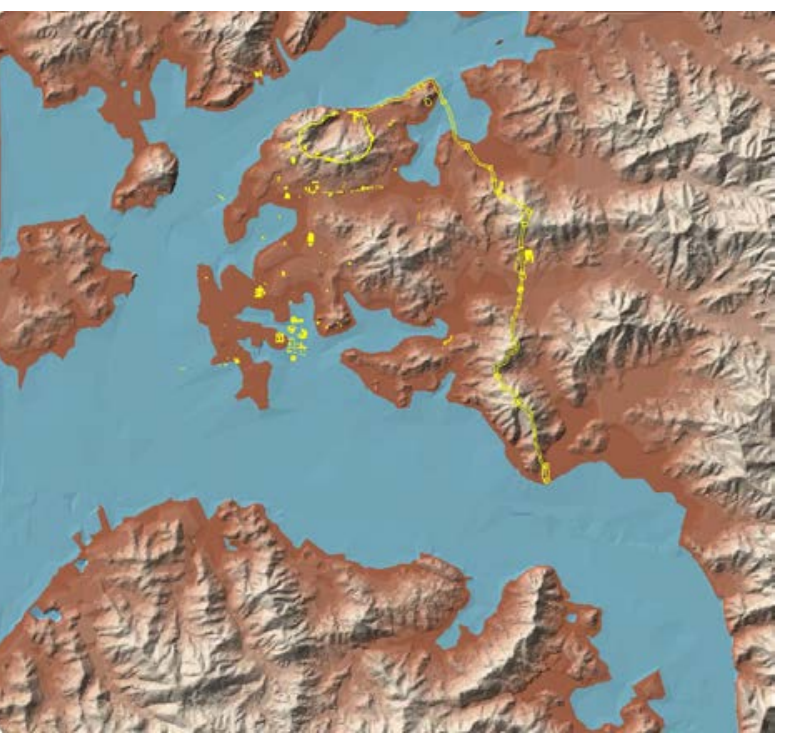

Figure 7. Ancient river boundaries during the flood season (water level is 9-7.5 m) 


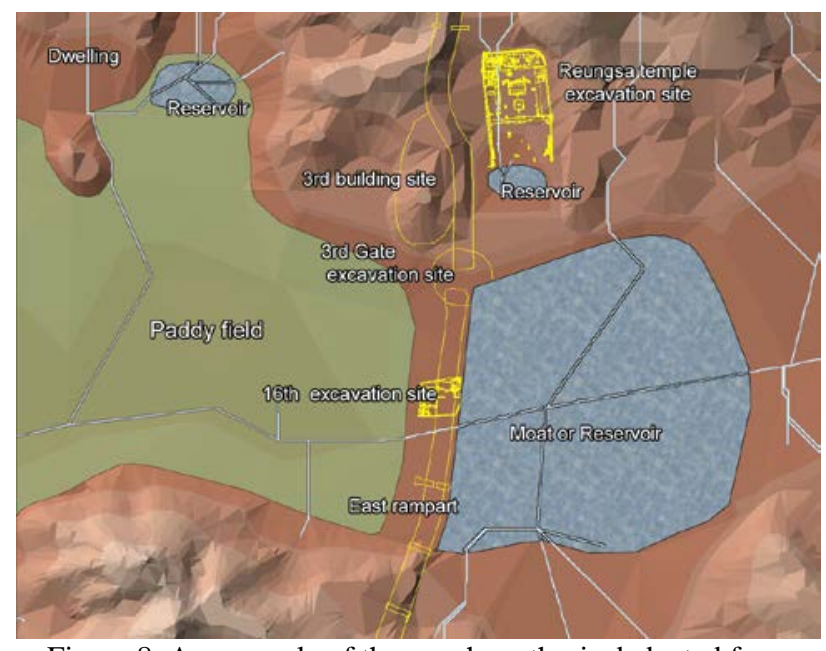

Figure 8. An example of the new hypothesis deducted from comparative analysis between the restored topography and the existing ruins

continuous water from the reservoir outside the western bank. The presented results (Figure 9) and a reinterpretation of the existing ruins suggest that the ancient topography of Buyeo was different from the present one; the previously assumed rectangular grid-type urban structure does not coincide with the restored topography. The lower area that supposedly had annual inundation was used as a rice field, and most structures were constructed above $10 \mathrm{~m}$ from the sea level. A dwelling site is now located for the first time on the mountain slope. The area underneath the present-day downtown Buyeo, which was assumed to hold significant ancient remains, was in fact a rice field and commercial site. Therefore, the new data provided here call for new excavation plans for the restoration of the historic city to progress further.

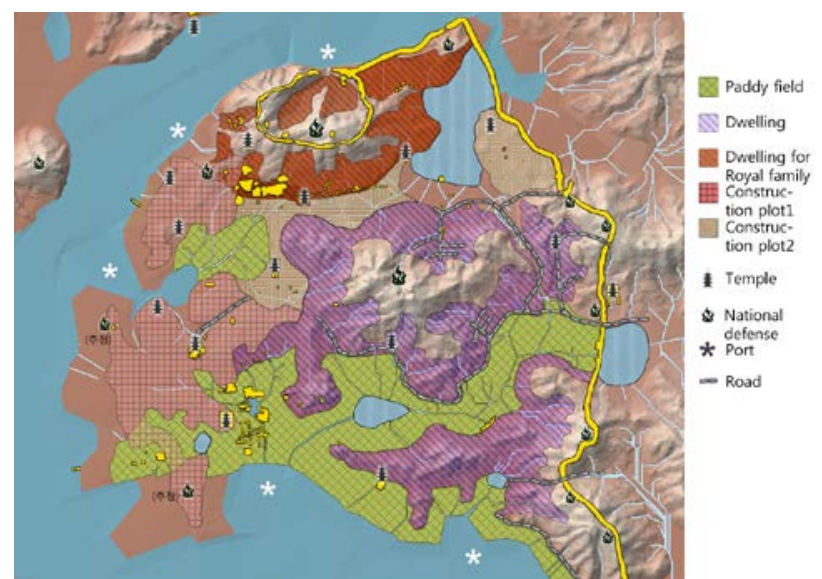

Figure 9. Land use in the ancient capital city, Sabi of Buyeo field. Even the downtown area of Buyeo that has been regarded as the central region of Sabi capital city was in fact a paddy field in ancient times. The dwelling area was rather located on the inclined plane of the mountain valley, which has never been considered and excavated thus far.

The present results indicate that in order to research a historic city properly, a topographic restoration is necessary. It provides researchers with complementary data to the existing study method and a precise analytical background. Furthermore, it reduces misconceptions and misinterpretations, which result from viewing only the present topography. In conclusion, it is expected that the topography restoration may aid in more efficient excavation plans and overcome the problem between conservation and development in historic cities.

\section{REFERENCES}

Buyeogun, 2009. The Baekma River, Buyeo, Korea.

Chungcheongnam-do history and culture center, 2007. Architecture and Civil Engineering of Baekje, Chungcheongnam-do history and culture center, Kongju, Korea.

Cho, W.C., 2011. Architecture and civil engineering of Baekje, Seokyeonmuwhasa, Seoul, Korea.

Gong, W.S. et al., 2011. Korean ancient paddy fields and irrigation facilities, Seogyeongmunhwasa, Seoul, Korea.

Hong, S.J., 1956. The Legend of Baekje, Tongmunkwan, Seoul, Korea.

Kim, J.Y. et al., 2005. Stratigraphy of wetland depositional sequence in Keum River Basin, Korea focused on Gungnamji, Sorori and Naeheungdong areas. Journal of the Hoseo Archaeological Society, 13(-), pp. 5-54.

Kim, Y.O., 1989. Korean Climate and Culture, Publishing department of Ewha Women's University, Seoul, Korea.

Korean Archeological Environment Labolatory et al., 2010. Korean Ancient Paddy Agriculture and Irrigation Facilityies, Seokyeongmoonhwasa, Seoul, Korea.

Kwon, H.J., 1975. A geographical study on the alluvial landforms of the Honam plain, Korea. Journal of the Korean Geographical Society, 10(2), pp. 1-20.

Lee, B.H., 2002. The expansion and development of the Baekje capital city Sabi-Doseong, Hankooksaron, 47(-), pp. 59-126.

Yoon, Y. et al., 1994. Joseon Folk Story, Hankukmunhwasa, Seoul, Korea.

\section{CONCLUSION}

Buyeo has undergone significant topographic changes from 663 $\mathrm{AD}$ until today. The reconstruction of the ancient topography reveals that the river was much wider and higher than today, and that substantial part of today urban areas were part of the river in the past.

Contrary to former belief, the Sabi capital city was planned and constructed, adapting to the ancient geomorphic context. The lowland was inundated annually; therefore, it was used as a rice 